\title{
Altas Habilidades/Superdotação e a psicopedagogia modular: avaliando potencialidades
}

Elizabeth Carvalho da Veiga*

\section{Resumo}

A psicopedagogia modular é uma proposta que apresenta um modelo de avaliação dinâmica, um processo interativo, flexível e individualizado, buscando compreender a funcionalidade dos sistemas inteligentes. A presente investigação foi realizada com crianças que buscaram avaliação psicopedagógica no Núcleo de Pratica em Psicologia da PUCPR e teve por objetivos apontar a funcionalidade dos sistemas inteligentes, reconhecendo a existência, ou não, de altas habilidades e identificar a predominância entre os sistemas analítico, prático ou criativo, utilizados pela clientela em questão. A metodologia de avaliação contou com os seguintes instrumentos: entrevista evolutiva modular; questionário para os pais; brasão familiar; E.M.C.A.; WISC III; provas multimodais e provas cognitivas modulares. Este processo levou aproximadamente 25 encontros de cinquenta minutos. Participaram da pesquisa 28 alunos de 8 a 17 anos de diferentes escolas de Curitiba - Paraná/Brasil. Por meio dos dados obtidos, ainda que apurados a partir de uma amostra pequena, pode-se concluir que a proposta da Psicopedagogia Modular, com seu modelo dinâmico de avaliação, favoreceu a identificação das altas habilidades/superdotação, na sua especificidade. Ou seja, considerando a multiplicidade dos sistemas inteligentes e as habilidades envolvidas nos processos mentais que sustentam as inteligências analítica, prática e criativa, a visão modular no processo de identificaçáo traz uma identidade ao superdotado, tirando-o da concepção generalista.

Palavras-chave: Superdotação; Psicopedagogia; Modularidade.

\footnotetext{
* Professora Doutora da Pontifícia Universidade Católica do Paraná (PUC). Curitiba, Paraná, Brasil.
} 


\section{Advanced Abilities/Giftedness and the modular psychopedagogy: evaluating potentialities}

\section{Abstract}

The modular psychopedagogy is a proposal that presents a model of dynamic assessment; it is an interactive, flexible and individualized process, which attempts to understand the functionality of intelligent systems. This research, conducted with children seeking psycho-pedagogical evaluation at the Center for Practical Psychology at PUC-PR, intended to point out the functionality of intelligent systems, identifying the existence or not of advanced skills, and to identify the prevalence among analytic, practical or creative systems used by the clients in question. The evaluation methodology included the following instruments: modular evolutionary interview; questionnaire for parents; family history; E.M.C.A; WISC III; multimodal and modular cognitive tests. This process took approximately 25 meetings of 50 minutes each. Twenty-eight students between 8 and 17 years old, from several Curitiba (Brazil) schools, participated in the survey. From the obtained data, albeit from a small sample, it is concluded that the proposed Modular Psychopedagogy, with its dynamic evaluation model, favored the identification of advanced ability/gifted individuals in its specificity, i.e. considering the multiplicity of intelligent systems and skills involved in the mental processes that underlie the analytical, creative and practical intelligences. The modular vision in the process brings an identity to the gifted, taking them out of the general conception.

Keywords: Giftedness; Psychopedagogy; Modularity.

\section{Introdução}

A ideia de superdotação esta atrelada ao conceito de inteligência. Por estar estreitamente relacionado com a definição de inteligência, compreende-se a dificuldade de existir uma definição consensual. A inquietação, em relação às altas habilidades/ superdotaçáo, motivou estudos e pesquisas, que deram origem a diversidade de concepçóes que, tentam explicar o fenômeno da superdotaçáo.

A admiração, e por que não dizer também a curiosidade sobre as pessoas com capacidades superiores, têm antecedentes antes de Cristo. Na Grécia e em Roma, crianças eram precocemente separadas das suas famílias para serem treinadas para a guerra ou para outras atividades nas quais se destacavam (GAMA, 2006. apud RANGNI; DA COSTA, 2011). O tema tem se caracterizado como um constante desafio, para os estudiosos desta área do conhecimento, pais e professores.

A história tem mostrado que a concepção de diversas teorias sobre a inteligência vem se configurando desde a psicometria, passando pelas teorias cognitivas, computacionais e modulares. A década de 80 marcou uma evolução na concepção da inteligência, considerando-a desde propriedade única da mente até uma arquitetura 
modular. A modularidade propóe uma mente constituída por um conjunto de módulos especializados, sistemas funcionais, inteligências múltiplas, memórias diversas. Para cada tipo de processo ou atividade têm-se estruturas específicas e especializadas.

Há necessidade de uma análise crítica referente à identificação da realidade multifacetada do superdotado. A evolução nos estudos sobre a inteligência humana desencadeia uma revisão no conceito cerebro-mente. Mudar de modo efetivo a noção de que a mente não é um sistema único, é uma das grandes provocaçôes à ciência moderna. Esta compreensão de uma mente modular, desencadeou a necessidade para a autora da Psicopedagogia Modular, Elizabeth Veiga, de rever o processo psicopedagógico e construir uma avaliação com base nas potencialidades, contrapondo as propostas tradicionalmente ocupadas pela psicologia, cujo foco está centrado no QI. Com base na visão pluralista da mente, passa-se a valorizar a observação e a mediação como meio de detectar as altas habilidades/superdotaçáo e para isso utiliza-se as provas cognitivas modulares (VEIGA et al, 2012).

Sistematizando os novos conhecimentos e estudos provenientes das pesquisas a respeito do cérebro e seu funcionamento, Veiga repensa a psicopedagogia sob a perspectiva da teoria modular da mente e, em 2005, junto com Emilio Garcia, lança A Psicopedagogia Modular (VEIGA, E. e GARCIA, E, 2005, 2006, 2010). Sua proposta psicopedagógica está voltada para a potencialização de todos os sistemas inteligentes do indivíduo, "descentralizando" o olhar do fracasso e focando em seu sucesso.

A psicopedagogia modular, leva em conta os processos mentais e as habilidades envolvidas em cada inteligência do modelo Triárquico de Sternberg relacionando-os com cada sistema inteligente proposto por Gardner (inteligência linguística, lógico-matemática, corporal-sinestésica, espacial, musical, naturalista, interpessoal e intrapessoal). Esta teoria integra três corpos teóricos: Teoria Triarquica da mente (STERNBERG, 1983, 1990, 1997), Teoria das Inteligências Múltiplas (GARDNER, 1988, 1992, 1995, 1997), e a Epistemologia Convergente de (VISCA, 1987).

Segundo Veiga e Garcia (2005, 2006), a proposta implica em mudanças na organização teórico-prática da psicopedagogia. O processo avaliativo propóe-se identificar como os processos mentais de cada inteligência estão atuando a partir do funcionamento das habilidades cognitivas correspondentes a cada processo mental, que, por sua vez, corresponde a uma determinada inteligência, propiciando o conhecimento das capacidades e dificuldades em cada sistema inteligente.

Um programa de avaliação para altas habilidades/superdotação deve estar relacionado diretamente com a concepção que se tem de superdotação. A proposta, aqui apresentada, tem como pressupostos básicos: a natureza do cérebro é modular; a inteligência não é uma capacidade única e sim múltipla; a inteligência acadêmica é apenas um tipo de inteligência.

Os interesses e habilidades em pessoas com altas habilidades/superdotação estão focados em cálculos matemáticos passando pelas artes, música, esporte, culinária, dentre outras áreas do conhecimento. Identificar os sistemas inteligentes tem sido, no momento, um desafio para os estudiosos das altas habilidades/superdotação, pois es- 
tas crianças carregam preconceitos fortes até os dias de hoje o que dificulta o trabalho de identificação, tornando-os invisíveis no ambiente escolar.

A avaliação, com base na psicopedagogia modular, é uma proposta que tem como objetivo redimensionar os esforços no campo da avaliação das altas habilidades/ superdotação. O foco desta avaliação está em descentralizar o modelo tradicional, que tem sua ênfase no QI, e que resulta em uma concepção generalista do fenômeno superdotação.

Esta pesquisa surgiu da necessidade de implantar um novo programa de avaliação com o intuito de responder a uma demanda que exige uma singularidade das altas habilidades/superdotação frente a uma concepção generalista de avaliação.

Na psicopedagogia modular, o aspecto cognitivo passa a ser compreendido como um sistema multidimensional, em que a mente esta organizada por um conjunto de sistemas e processos específicos para resolver diferentes tipos de problemas. A avaliação se estabelece num diálogo proposto pela autora da Psicopedagpgia Modular entre a teoria de Gardner e a teoria de Sternberg.

A avaliaçáo contou com o treinamento dos estagiários do Núcleo de Pratica em Psicologia (NPP) que participaram da pesquisa. Durante 3 meses, estes estagiários passaram por um acompanhamento a respeito dos instrumentos a serem utilizados no processo. Após o domínio dos instrumentos pelo grupo, as crianças que buscavam o serviço de avaliação psicopedagogica do NPP eram encaminhadas para os estagiários iniciarem a avaliação.

O processo de avaliação esta composto por 5 etapas. A primeira é denominada de Entrevista Evolutiva Modular. Este procedimento consta em um roteiro de perguntas focadas no desenvolvimento da criança, focando aspectos de precocidade, antecedentes familiares, perguntas especificas para levantamento de informaçóes da inteligência intrapessoal, interpessoal e da inteligência suspeita de altas habilidades/ superdotação. Este processo leva, em média, de uma a duas sessôes com os pais ou responsáveis. Os dados obtidos nesta entrevista, são relacionados com os oito sistemas inteligentes de Gardner. Ao final da entrevista, é entregue aos responsáveis o Questionário para Pais, o qual deve ser respondido e devolvido na sessão seguinte. É um recurso utilizado para complementar as informaçóes direcionadas aos oito sistemas inteligentes.

A segunda etapa é o brasão familiar, procedimento realizado em uma sessão junto à família, com a finalidade de levantar os aspectos funcionais da família, seus valores e sua compreensão de superdotação. É solicitado que a família desenhe um brasão em que conste os valores da família e, em seguida, que a mesma construa uma imagem que represente a superdotação para aquele sistema familiar.

A terceira sessão é a E.M.C.A., entrevista modular centrada na aprendizagem. Segundo Veiga e Garcia (2006, 2005) e Veiga et al. (2012), a EMCA é uma entrevista realizada com a criança e requer um ambiente que deve ofertar recursos que contemplem as 08 inteligências. Pode ser individual ou em grupo e apresenta duas modalida- 
des de consigna de acordo com a idade da criança. O objetivo da EMCA é identificar a ou as inteligências que a criança utiliza para resolver suas tarefas cognitivas, quais são as facilidades e dificuldades encontradas em seu uso, bem como auxiliar a criança a descobrir as outras potencialidades cognitivas para solucionar as tarefas.

A partir da quarta sessão, é realizada a aplicação do teste de inteligência WISC III, com a análise fatorial: compreensão verbal, organização perceptual, resistência à distrabilidade e velocidade processual. Após a aplicação do WISC III, são utilizadas as provas cognitivas modulares e as provas multimodais (VEIGA et al. 2012).

Tanto os instrumentos formais, como os informais, são importantes. O profissional pode explorar mais sobre o sistema cognitivo do sujeito nas provas cognitivas modulares e nas multimodais, do que é normalmente registrado nas medidas formais. $\mathrm{O}$ uso de instrumentos informais dá ao indivíduo a oportunidade para mostrar o funcionamento dos sistemas inteligentes por meio de várias modalidades.

A avaliação modular procura imergir o sujeito durante um período em um ambiente enriquecido de recursos centrados nas 8 inteligências e avaliar seu desempenho, integrando as inteligências de Gardner e as de Sternberg, para conhecer suas verdadeiras potencialidades numa abordagem mais holística.

Sem perder de vista a complexidade universal do tema superdotação, os resultados mostraram que 38,7\% apresentaram altas habilidades/superdotação e 62,3\% revelaram dificuldades de aprendizagem sem o diagnóstico de altas habilidades/superdotação. Este resultado nos reporta à necessidade de capacitar os profissionais da educação para auxiliá-los neste processo de reconhecimento desses sujeitos com indicativos de altas habilidades/superdotação, pois todos os sujeitos que participaram desta pesquisa, procuraram o NPP para avaliar as dificuldades de aprendizagem no contexto escolar. Entre os sujeitos que apresentaram altas habilidades/superdotação, quatro deles também revelaram dificuldades de aprendizagem nos sistemas linguísticos e logico-matemáticos.

Por meio da avaliação pode-se identificar um predomínio da inteligência prática em relação a inteligência analítica e a inteligência criativa. Este dado vai na contra mão da literatura sobre altas habilidades/superdotação que aponta como característica a criatividade. Neste grupo pesquisado foi a inteligência que menos se destacou. Considerando que a criatividade não é potencializada nos sistemas educativos, nos parece compreensível este resultado.

Considerando os oito sistemas inteligentes de Gardner, destaca-se a inteligência Linguística, seguida das inteligências Lógico-matemática e Espacial; na sequência vem a inteligência Interpessoal e Musical.

Após a realização desta pesquisa, instituiu-se no NPP o PADISM - Programa de Avaliação Dinâmica para Identificaçáo de Superdotados com base na Modularidade da Mente, que visa atender crianças e/ou adolescentes com indicadores de altas habilidades/superdotação. É um programa que visa redimensionar os esforços no campo da avaliação das altas habilidades/superdotação. A necessidade da implantaçấo 
desse programa surgiu com o intuito de responder a uma demanda que exige uma singularidade das altas habilidades/superdotação frente a uma concepção generalista de avaliação. Esse programa está baseado na psicopedagogia modular.

\section{Considerações finais}

A avaliação com base na psicopedagogia modular favoreceu a identificação das pessoas com altas habilidades/superdotação. Por meio da entrevista evolutiva modular identificou-se 2 aspectos importantes: a precocidade e dados referentes a questóes genéticas. A identificaçáo dos sistemas inteligentes e o predomínio entre os sistemas analítico, prático e criativo, tanto o questionário preenchido pelos pais, bem como as provas multimodais e provas cognitivas modulares, trouxeram informaçóes que contribuíram na identificação do sistema ou sistemas de destaque, relacionando aos processos mentais das inteligências, analítica, pratica e criativa, que foram predominantes na execução das tarefas.

Nem todas as crianças diagnosticadas com altas habilidades/superdotação atingiram o QI 130. O processo revelou que fatores como perfeccionismo, rigidez, podem interferir no resultado. Isso nos leva a pensar nas avaliaçóes centradas apenas em testes de inteligência .

As crianças com altas habilidades/superdotação mostraram-se mais questionadoras, curiosas, atentas a tudo, em comparação com as crianças com dificuldades de aprendizagem. Constatou-se que, na maioria das crianças ou adolescentes com altas habilidades/superdotaçáo, há uma tendência à introspecção. Apesar da dificuldade de relacionamento retratado na avaliaçáo, estes sujeitos demonstraram uma vontade de "pertencer" ao grupo, em especial os adolescentes, e de serem aceitos.

Os dados encontrados trazem informaçóes relevantes para as altas habilidades/ superdotação e seus processos de identificação. Ademais, oferecem contribuição para o desenvolvimento de açôes educativas que colaborem nesta árdua tarefa de identificar, alertando sobre os prejuízos relacionados a não identificaçáo, pois, neste estudo, $38,7 \%$ destas crianças eram invisíveis no contexto escolar no que diz respeito as suas potencialidades, consequentemente um desperdício do capital humano, riqueza incontestável para o desenvolvimento de um pais.

\section{Referências}

GARDNER, H. La mente no escolarizada. Barcelona: Paidós, 1997

Inteligencias múltiples. La teoría en la práctica. Barcelona: Paidós, 1995.

Estructuras de la mente. México: FCE, 1992.

La nueva ciencia de la mente. Barcelona: Paidós. 1988

RANGNI, R. A.; DA COSTA, M. P. R., A Educação dos Superdotados: História e Exclusão, Revista Educação, UnG, v. 6, n. 2, 2011.

STERNBERG, J. R. Inteligencia exitosa. Barcelona: Paidós, 1997.

Metaphors of mind: conception of the nature of intelligence. Cambridge: University Press, 1991.

Mas alla del cociente inteligente. Bilbao: Biblioteca de Psicologia: 1990. 
STERNBERG, J. R. Intelligence applied: understanding and increasing your intellectual skills. New York: Harcourt, 1986.

STERNBERG, R. J. (1983). Components of human intelligence. Cognit, 15, 1-4.

VEIGA, E.; GARCIA, E. Psicopedagogia e a teoria modular. Educación, Desarrollo y Diversidad, MadridEsp, v. 8, p. 55-72, abr. 2005.

Psicopedagogia e a modularidade da mente. São José dos Campos: Pulso, 2006.

VEIGA, E. C. da. A Psicopedagogia Modular: uma nova perspectiva no campo da avaliaçáo. Psicologia Argumento, Curitiba, v. 28, n. 60, p. 11-15, jan./mar. 2010.

VEIGA, E. C. da et al. Psicopedagogia Modular: uma modalidade de avaliaçáo interventiva. Curitiba. Ed Vozes e Ed. Champagnat. 2012

VISCA, J. Clínica Psicopedagógica e Epistemologia Convergente. Porto Alegre: Artes Médicas. 1987

\section{Correspondência}

Elizabeth Carvalho da Veiga - Pontifícia Universidade Católica do Paraná, Reitoria, Instituto de Ciências Biológicas e da Saúde. Rua Imaculada Conceição, 1155, Prado Velho, CEP: 80215-190 - Curitiba, Paraná - Brasil.

E-mail: bethveiga@hotmail.com

Recebido em 03 de abril de 2014

Aprovado em 27 de junho de 2014 
